\title{
O VALOR DO SUPORTE À PARTURIENTE: UM ESTUDO DA RELAÇÃO INTERPESSOAL NO CONTEXTO DE UM CENTRO DE PARTO NORMAL*
}

\section{THE VALUE OF SUPPORT CARE FOR THE PARTURIENT WOMAN: A STUDY ON INTERPERSONAL RELATIONSHIP IN THE CONTEXT OF A NORMAL DELIVERY CENTER.}

Ana Verônica R Silva**

Arnaldo A F de Siqueira ${ }^{* * *}$

\begin{abstract}
Silva AVR, Siqueira AAFd. O valor do suporte à parturiente: um estudo da relação interpessoal no contexto de um Centro de Parto Normal. Rev Bras Crescimento Desenvolv Hum 2007;17(1):126-135.
\end{abstract}

Resumo: Uma importante questão que vem sendo apontada nos estudos sobre as práticas assistenciais em saúde é a que se refere à influência considerável da dimensão relacional na qualidade dos cuidados prestados. O suporte emocional e social no ciclo gravidez-puerpério, especialmente durante o trabalho de parto e parto, tem sido valorizado em muitos estudos em diversos países, com diferentes modalidades de suporte institucional, como um fator importante na qualificação da assistência materna. Este artigo apresenta resultados e considerações sobre o tema do suporte com base em estudo realizado em maternidade de São Paulo, em 2004, utilizando metodologia qualitativa com entrevista semi-estruturada e observação de rotinas da instituição. O processamento dos dados valeu-se de categorias formuladas para análise, que mostrou a relevância das relações interpessoais no processo da parturição possibilitando apreender o espaço relacional como lugar privilegiado de interlocução marcada pela escuta e acolhimento da experiência vivida, podendo ser considerado entre aqueles recursos, de significativa importância, indicados como apropriados na assistência ao parto.

Palavras-chave: Parto. Trabalho de parto. Suporte/apoio. Qualidade dos cuidados de saúde.

\section{INTRODUÇÃO}

Estudos sobre as questões relativas ao parto e sua assistência vem pontuando situações estudadas que se configuram como problemas relevantes de saúde pública: altos coeficientes de mortalidade materna em todas as regiões do país, altas taxas de cesárea, déficit de leitos de maternidade, pré-natal pouco qualificado, precária organização do sistema de saúde, entre outros. ${ }^{1,2} \mathrm{O}$ enfrentamento das adversidades presentes na assistência à saúde materna tem envolvido inicia- tivas de órgãos governamentais brasileiros, organismos internacionais, universidades, sociedade civil através de associações de profissionais e dos movimentos sociais organizados.

Assim, o Programa de Maternidade Segura da Organização Mundial de Saúde (OMS) adotado pelo Ministério de Saúde tem no documento "Assistência ao parto normal: um guia prático" 3 uma referência orientadora. Identificando práticas freqüentemente utilizadas o guia apresenta normas para o que denomina "boas práticas" no manejo do processo do trabalho do "parto normal".

\footnotetext{
* Artigo baseado em tese de Doutorado: "O suporte à parturiente: a dimensão interpessoal no contexto da assistência ao parto”. 2004. Faculdade de Saúde Pública da Universidade de São Paulo, Departamento de Saúde MaternoInfantil. e-mail: anavero@usp.br

** Psicóloga, Doutora em Saúde Pública.

*** Professor Titular do Departamento de Saúde Materno Infantil da Faculdade de Saúde Pública da USP.
} 
É interessante notar que, embora a questão do bem-estar materno percorra todos os itens tratados no documento, os aspectos emocionais no recorte das relações interpessoais são especificamente mencionados nas considerações sobre alguns métodos de alívio da dor no trabalho de parto - "quase todas as mulheres sentem dor durante o trabalho de parto" (...) uma tarefa importante do parteiro é ajudar as mulheres a suportar a dor durante o trabalho de parto" ${ }^{3}$ (OMS, 1996). As recomendações enfatizam, além do apoio, os métodos não invasivos e não farmacológicos de alívio da dor do parto. Os aspectos emocionais também são referidos nas recomendações relativas ao planejamento do parto que deve ser feito em conjunto com a gestante e família durante o pré-natal. Quanto ao local do parto, o documento chama a atenção para as características físicas e de acolhimento relacional favoráveis ao bem-estar psicológico das mulheres e, nessa mesma direção, traz observações quanto aos cuidados imediatos com o recém-nascido que incluem a promoção do contato mãe-bebê logo após o nascimento.

Cabe lembrar ainda o manual "Parto, aborto e puerpério: assistência humanizada à mulher", do Ministério da Saúde ${ }^{4}$, que divulga conceitos, princípios e parâmetros da atenção à saúde materna. Ressalte-se que o referido documento aborda, entre outras questões, o tema do acompanhamento - ou "suporte psicossocial" das mulheres durante o trabalho de parto na perspectiva do direito, já instituído por lei e reconhecido, mas não praticado sistematicamente no país. O manual também faz referência específica ao acompanhamento realizado por pessoa - a doula designada e treinada para esse fim pela instituição de saúde ou pela comunidade. O Ministério da Saúde ${ }^{4}$ assim propõe como atribuições da acompanhante treinada: Durante o trabalho de parto $e$ parto, a acompanhante: orienta a mulher a assumir a posição que mais lhe agrade durante as contrações; favorece a manutenção de um ambiente tranqüilo e acolhedor, com silêncio e privacidade; auxilia na utilização de técnicas respiratórias, massagens e banhos mornos; orienta a mulher sobre os métodos para o alívio da dor que podem ser utilizados, se necessários; estimula a participação do marido ou compa- nheiro em todo o processo; apóia e orienta a mulher durante todo o periodo expulsivo, incluindo a possibilidade da liberdade de escolha quanto à posição a ser adotada (Ministério da Saúde , 2001).

Vale destacar também medidas na esfera do Poder Legislativo ${ }^{5}$, entre as quais encontrase a recente Lei n. 11.108, de 7 de abril de 2005, que assegura a presença de um acompanhante de escolha da parturiente, em toda a rede dos serviços de saúde do SUS , no período que se estende desde o trabalho de parto até o pós-parto imediato.

\section{Relações interpessoais nas práticas de saúde}

Uma importante questão que vem sendo apontada nos estudos sobre as práticas assistenciais em saúde é a que se refere à influência considerável da dimensão relacional na qualidade dos cuidados prestados. Da miríade de temas, questões, problemas teóricos e técnicos afeitos ao universo das relações interpessoais, estudados pelas ciências designadas genericamente por Humanidades, o tema da relação interpessoal na situação específica de prestação de cuidados de saúde recoloca-se no contexto da produção teórica e crítica dos discursos e práticas de saúde em uso na contemporaneidade.

Caprara e Franco ${ }^{6}$ situam o desenvolvimento do tema a partir das contribuições, na década de 1950, do médico e filósofo Karl Jaspers, que propunha a necessidade da recuperação dos aspectos subjetivos da comunicação entre o médico e o paciente, negligenciados pela medicina da era da técnica. Para esses autores a temática das relações interpessoais tem sido focalizada como elemento decisivo para uma melhor qualificação do serviço de saúde. Outras contribuições apontadas são os aportes dos estudos da psicologia médica e da psicanálise - destacando-se trabalho dos grupos Balint ${ }^{7}$ - assim como também os estudos na área da sociologia da saúde e da antropologia.

Nos estudos atuais, de acordo com os autores ${ }^{6}$, são destacados aspectos como: a personalização da assistência; a humanização do atendimento; o direito à informação; o grau de satisfação do usuário dos serviços de saúde; o sofrimento 
do paciente e a finalidade da biomedicina; o aconselhamento (counselling); o consentimento informado.

As elaborações da Psicologia e da Psicanálise têm contribuído largamente para o aprofundamento, compreensão e consciência da complexidade desse universo. Autores como Winnicott e Balint destacaram-se, entre outros pontos, pelo estreitamento do diálogo de suas elaborações teóricas e técnicas com outros saberes. Ressaltese que a prática clínica decorrente do reconhecimento das formulações winnicottianas permitiu sua expansão para situações em que, embora distintas das práticas psicoterápicas estrito senso, os cuidados de saúde são prestados caracterizando-se igualmente como situações perpassadas pelo jogo interativo da relação interpessoal isto é, pelo jogo entre as identificações e contraidentifícações dos envolvidos.

Seguindo o pensamento de Winnicott ${ }^{8} \mathrm{e}$ de Balint ${ }^{9,10}$, no que diz respeito ao lugar das relações interpessoais nas interações sociais, marcadamente naquelas interações que implicam provimento de cuidados, pode-se presumir que as suas contribuições guardariam afinidades com temáticas, crescentemente presentes no debate sobre as práticas médicas e de saúde, como a questão da humanização da assistência, especialmente da assistência ao parto.

Embora polissêmico, o termo humanização tem nas relações humanas o seu centro de referência quando se fala, por exemplo, em "humanizar" as cidades, empresas, escolas ou hospitais. No contexto da saúde, a abordagem do paciente dentro dos princípios e valores humanísticos tem sido associada ao cuidado sensível, centrado na pessoa e nas relações interpessoais.

Diniz ${ }^{11}$ sublinha a diversidade de acepções no uso do termo por profissionais; formuladores e gestores de políticas públicas; administradores de hospitais públicos e privados; movimentos sociais; mídia; consumidores. Os debates em torno dos sentidos que assume o termo humanização refletem dissensões tanto em relação às práticas obstétricas utilizadas, como também a visões sobre o processo saúde-doença e seus determinantes e, dentro desse espectro, sobre a saúde da mulher, o parto e seus significados, suas dores e temores.

\section{O suporte à parturiente}

Sofrimento, dor, agonia, provação, terror, morte são termos historicamente associados às vivências do trabalho de parto e do parto. Os temores e inseguranças da mulher, que emergem durante a gravidez, não costumam ser objeto de cuidado na atenção ao pré-natal. Ao contrário, "são mais estimulados do que prevenidos no pré-natal que ela recebe e no contexto social em que ela passa sua gravidez", afirmam Faúndes e Cecatti ${ }^{2}$ (1991). Os autores mencionam ainda a importância de um trabalho psicológico que a assistência no pré-natal poderia oferecer visando o fortalecimento emocional da mulher para o parto.

A demanda pelo alívio da dor do parto figura como um dos aspectos em torno do qual o acompanhamento contínuo assume grande relevância. Entretanto, o conhecimento sobre a natureza da dor do parto e o seu manejo apresenta-se, em muitos estudos ${ }^{12,13}$, sob debate e controvérsias, sobretudo no tocante à segurança dos procedimentos e efetividade dos métodos usados . Importa também levar em conta que a experiência da dor do parto caracteriza-se como uma complexa, subjetiva e multidimensional resposta a estímulos no processo da parturição ${ }^{13}$.

Discutindo a importância dos fatores psicológicos Lowe ${ }^{13}$ analisa o papel da ansiedade no aumento da dor durante o trabalho de parto, referindo que se admite como normal a presença de um certo nível de ansiedade nas mulheres nesta situação, e como nocivo níveis considerados excessivos, dado que nesta condição a ansiedade pode modificar inclusive os mecanismos fisiológicos da dor do parto.

Para Faúndes e Cecatti ${ }^{2}$ o temor da dor do parto, quando intensificado por fatores adicionais, pode torná-la de tal modo insuportável que o momento do nascimento é convertido em algo aterrorizante levando, por exemplo, muitas mulheres à escolha do parto cirúrgico quando este não está claramente indicado, do ponto de vista obstétrico. A literatura aponta outros efeitos ou sinais do medo da dor, ainda que eles não derivem para ações concretas como, por exemplo, buscar um parto cirúrgico. Por outro lado, as idéias de aniquilamento, fragilidade, desfalecimento, morte 
e outros imaginados perigos como danos ao corpo, possíveis defeitos físicos do feto são observados e tematizados por muitos autores como Soifer ${ }^{14}$, Noronha ${ }^{15}$, Maldonado ${ }^{16}$ e Langer ${ }^{17}$, pensamentos esses que são fontes, eles mesmos, de ansiedade e contribuem enormemente para a elevação do grau de angústia e de constrangimento psicológico.

Vale considerar que, levar em conta a eclosão de aspectos psicogênicos durante o trabalho de parto e parto - que, por sua natureza e grau de intensidade, assumem o caráter de descompensação ou de desestabilização psicológica não significa interpretá-los com o crivo da psicopatologia ou de outras teorias normalizadoras do comportamento humano. As práticas interpretativas fundadas nesses princípios parecem aproximar-se daquelas práticas medicalizantes do ciclo gravidez-puerpério e que vêm sendo consideradas inadequadas.

Historicamente constatou-se uma inflexão nas práticas da assistência à mulher parturiente a partir do momento em que o parto passou a ser realizado em instituições hospitalares, conforme Klaus e Kenell ${ }^{18}$. Dentre as práticas que foram alteradas os autores destacam o uso de medicação obstétrica e o acompanhamento do trabalho de parto por outra mulher.

O suporte emocional e social no ciclo gravídico-puerperal, especialmente durante o trabalho de parto e parto, tem sido referido e valorizado em diversos estudos ${ }^{18-20}$ como um fator importante na qualificação da assistência materna e os seus efeitos vêm sendo detalhadamente investigados nos últimos anos. Em diversos países, com diferentes modalidades de suporte institucional, os estudos realizados têm encontrado impacto positivo de tal suporte na experiência emocional da mãe, na evolução do trabalho de parto e parto, nas condições de saúde do bebê ${ }^{19,20}$.

Entre as variadas questões em torno do acompanhamento continuado destacam-se aquelas que tentam responder se o suporte, físico e emocional, oferecido modifica os resultados obstétricos e neonatais.

Em revisão sistemática de 11 estudos realizados em países como Canadá, Bélgica, África do Sul, Finlândia, Grécia, França, Guatemala e Estados Unidos, alguns resultados encontrados indicaram diferenças nos grupos de mulheres que receberam suporte comparativamente aos que não o receberam. Entre os resultados assinalaram-se aqueles que mostraram decréscimo nas taxas de cesárea e do uso de analgesia ${ }^{18}$.

Ainda sobre a investigação das possibilidades e alcances do acompanhamento contínuo Hodnett et al. ${ }^{20}$ analisaram estudos com o objetivo central de avaliar os efeitos do suporte continuado, oferecido por doulas, sobre a mãe e o bebê e, como objetivo secundário, estabelecer se tal suporte seria influenciado por: a) políticas e rotinas da instituição afetando a autonomia, liberdade, movimentação e habilidade da mulher em lidar com o trabalho de parto; b) se o provedor do suporte seria ou não funcionário da instituição; c) se o suporte foi oferecido no início ou nos estágios posteriores do trabalho de parto. Tal revisão totalizou 15 estudos com os mesmos parâmetros metodológicos, comparando os dados dos grupos que tiveram suporte continuado com os dados dos serviços comuns de saúde, envolvendo 12.791 mulheres. Os dados foram coletados de estudos registrados no Cochrane Collaboration Pregnancy and Childbirth Group e no Cochrane Central Register of Controlled Trials, em 2003.

Como resultados principais da análise comparativa, os autores ${ }^{20}$ estabeleceram que as mulheres do grupo com suporte contínuo receberam menos analgesia, reportaram menos insatisfação com a experiência do parto e houve menos parto cirúrgico. Outros resultados apontaram, segundo os autores, a associação do suporte continuado com maiores benefícios quando o provedor-doula não era funcionário da instituição; quando o suporte teve início nos primeiros estágios do trabalho de parto e quando ocorreu em instituições que não usavam anestesia peridural como procedimento rotineiro.

No que diz respeito aos fatores ambientais, Lowe ${ }^{13}$ propõe que o reconhecimento da enorme influência de tais fatores na experiência da parturiente advogando a realização de mais estudos sobre a questão que poderão levar à adoção de intervenções propícias ao enfrentamento da dor do parto. A noção de ambiente de que se trata inclui: a comunicação verbal e não-verbal entre as pessoas; a filosofia que orienta os proce- 
dimentos e as práticas dos provedores; a qualidade do suporte oferecido e percebido pelas mulheres; o grau de estranhamento com o ambiente (equipamentos, mobiliário, barulhos, iluminação, temperatura, dimensões do espaço e sua adequação para movimentação, deambulação).

O presente artigo apresenta considerações sobre o tema do suporte emocional oferecido às parturientes cotejando o valor da relação interpessoal durante o trabalho de parto e no parto, tendo como base os dados e resultados de estudo realizado em uma maternidade de São Paulo, em 2004. A perspectiva de análise do referido estudo identifica-se com a visão do lugar privilegiado que ocupa a escuta compreensiva dos emergentes aspectos psicológicos e emocionais, em um momento específico e especial da vida das mulheres (e dos homens). O lugar, portanto, das relações interpessoais e suas potencialidades na travessia desta situação.

As aproximações ao problema da investigação permitiram formular algumas indagações em torno de qual seria esse lugar da interação provedor de cuidados-paciente na presença de fatores estressantes como, por exemplo, dor intensa, medo do que vai acontecer, estranhamento com o ambiente, suspensão temporária do contato de pessoas com quem se construiu laços afetivos, entre outros. Seria possível dizer que, em determinadas condições como trabalho de parto prolongado, doloroso, complicado, a qualidade da interação provedor de cuidados-paciente teria alguma influência no alívio do mal-estar vivido?

\section{Sujeitos e métodos}

A pesquisa realizada caracterizou-se como um estudo descritivo e analítico valendo-se de metodologia qualitativa Os dados produzidos foram obtidos por meio de entrevistas, na modalidade de entrevista semi-estruturada, com parturientes e provedores de cuidados - as doulas - e de observação livre, direta e participante das interações e dinâmica das rotinas da instituição de ocorrência do estudo.

Foram entrevistadas 20 parturientes que tiveram parto por via vaginal em um Centro de Parto Normal (CPN) de uma maternidade na cidade de São Paulo, em 2004. Dentre os provedores de cuidados, a escolha recaiu sobre o grupo de doulas por reunir características, observadas no período da pesquisa exploratória, que se julgou adequadas às intenções do estudo. Entre essas características, algumas atribuições delegadas e incorporadas como práticas específicas desse grupo tais como: assegurar a presença continuada junto às parturientes; oferecer apoio emocional, psicológico, massagens; intermediar a comunicação com os familiares que esperam fora do Centro.

Todas aquelas parturientes abordadas com a solicitação para entrevista aquiesceram tendo sido combinado encontro para o dia seguinte no setor de puerpério. Assim, as entrevistas foram realizadas no período puerperal, mais precisamente decorridas entre 24 e 30 horas do momento do parto.

Os parâmetros para a pesquisa envolvendo seres humanos estabelecidos pela Resolução 196/ 96 do Conselho Nacional de Saúde/Ministério da Saúde foram observados e aprovados pelo Comitê de Ética em Pesquisa da Faculdade de Saúde Pública/USP. De acordo com o estabelecido nas normas, as entrevistas foram realizadas após a informação sobre o que era e quais os objetivos da pesquisa, conforme consta no Termo de Consentimento Livre e Esclarecido que foi lido e assinado. Do mesmo modo, a solicitação de autorização para a realização da pesquisa foi encaminhada aos responsáveis pela instituição de ocorrência do estudo sendo obtida a permissão pleiteada.

\section{Processamento dos dados}

As entrevistas foram gravadas e transcritas pela pesquisadora ao longo do tempo do trabalho de campo. Para a análise dos dados empíricos do estudo, recorreu-se às indicações de Queiroz ${ }^{21} \mathrm{e}$ Minayo ${ }^{22}$ concernentes à técnica de análise de conteúdo/análise temática tendo como eixo a identificação de unidades de significado nas falas das parturientes e doulas. Como resultado das sucessivas leituras elaborou-se uma lista inicial (start list) de tópicos referidos às categorias gerais relacionadas às questões da pesquisa, problemática colocada, à referência teórica do estudo e 
à hipótese apresentada, conforme indicado por Miles e Huberman ${ }^{23}$. Assim, foi construído um quadro classificatório e posteriormente elaborouse o esquema de categorias para a análise dos dados. O quadro geral de categorias foi assim formulado: subjetividade; intersubjetividade (subjetividade no contexto relacional, referências à presença do outro); acolhimento; apropriação da experiência. Adotou-se a definição do termo subjetividade como segue: "o caráter de todos os fenômenos psíquicos, enquanto fenômenos de consciência (v.) isto é, tais que o sujeito os refere a si mesmo e os chama de "meus' "(Abbagnano $\left.{ }^{24}\right)$. É oportuno ressaltar que a análise desenvolvida incidiu sobre o conteúdo manifesto dos depoimentos.

Vale lembrar, ainda, que no recorte proposto no estudo para designar os aspectos da subjetividadade esteve presente a concepção de que a subjetividade e sua formação se inscrevem no campo das relações sociais e que tal pertinência impõe o entendimento da sobredeterminação e da complexidade na dinâmica interacional desses aspectos no âmbito subjetivo.

\section{RESULTADOS}

\section{Dados situacionais}

As idades das parturientes variaram entre 15 a 36 anos. Quanto ao grau de instrução escolar, a maioria das 20 mulheres entrevistadas apresentou escolaridade em nível de segundo grau sendo que quatro parturientes o concluíram e sete não o concluíram. Entre as nove com instrução escolar no nível do ensino fundamental, duas o completaram e sete não o completaram.

Com relação à situação conjugal, a união consensual foi predominante, sendo esta a situação apresentada por 10 das mulheres do estudo. Entre as demais, seis eram casadas e quatro solteiras. Com respeito ao número de filhos, foi expressivo o número de mulheres com um filho sendo que: 11 mulheres estavam experienciando sua primeira gestação; duas mulheres na segunda gestação, com história de aborto em gestação anterior e uma na terceira gestação, com dois abor- tos anteriores. A totalidade das mulheres participantes do estudo realizaram pré-natal, variando entre elas a idade gestacional do início e o número de consultas realizadas, com predominância entre 5-8 consultas. As unidades da rede básica do Sistema Único de Saúde, situadas em diferentes regiões da cidade de São Paulo, foram os locais onde ocorreram as consultas do pré-natal. Quanto ao percurso feito em busca da instituição para o parto a expressiva maioria (17) procurou o hospital/maternidade ou por proximidade de seus domicílios, ou por ter tido boas referências da instituição contatada. Na grande maioria dos casos, porém, por indisponibilidade de vagas, as parturientes foram transferidas, em ambulância, para a maternidade Amparo Maternal. Com respeito à duração do trabalho de parto “ estimada para o período entre a formalização da internação até o momento do nascimento "o tempo médio concentrou-se no intervalo entre 11 e 17 horas.

No grupo das sete doulas entrevistadas a faixa etária oscilou entre 36 e 67 anos. A escolaridade variou entre $2^{\circ}$ e $3^{\circ}$ graus completos. $\mathrm{O}$ grupo também apresentou-se de maneira diversificada quanto à profissão ou ocupação. A grande maioria das entrevistadas vinha exercendo atividades como doula na instituição desde há um ano, tendo o seu vínculo institucional caráter de trabalho voluntário.

A maternidade Amparo Maternal foi estabelecida como instituição beneficente desde sua fundação, em 1939, sendo detentora do status jurídico de Entidade Filantrópica de Utilidade Pública Municipal, Estadual e Federal. Integra a rede de maternidades que atendem pelo Sistema Único de Saúde. A instituição dispõe de 150 leitos de obstetrícia, sendo 24 destes alocados no Centro de Parto Normal (CPN), implantado em 1999, onde são realizados apenas partos vaginais sob a responsabilidade de obstetrizes. O CPN conta com sete salas de parto, 11 banheiros com duchas, duas banheiras de hidromassagem, quartos amplos e espaço para deambulação das parturientes. Dispõe também de alguns artefatos utilizados como recurso no auxílio à evolução do trabalho de parto, tais como banco obstétrico, bolas. 


\section{Sobre os dizeres}

A análise dos dados obtidos mostrou que um considerável grau de estresse foi experimentado pelas parturientes durante o trabalho de parto e parto. $\mathrm{O}$ medo e a dor figuraram como agentes estressores preponderantes nos relatos. Tal estado de tensão foi vivido como de grande sofrimento para o qual contribuíram, certamente, numerosos fatores, entre os quais, os processos fisiológicos da parturição, sentidos como insuportavelmente dolorosos, assim como os processos psicológicos sinalizados por manifestações de angústia e ansiedade e pelo que foi recorrentemente referido como medo, percebido como não menos doloroso, segundo os depoimentos - medo da dor, da morte, dos agravos à saúde, de imperfeições.

Mencionada na quase totalidade das entrevistas a dor foi qualificada como muito intensa "insuportável", "a pior dor" e, para quase a metade das parturientes, relatada adicionalmente como experiência de grande sofrimento.

A alusão ao medo, no entanto, apareceu associada a diferentes motivos e a idéias de perigos diversos tais como a idéia de iminência de morte, própria e/ou do bebê, que foi citada de modo significativo. Em alguns casos, a menção ao medo de algo difuso, desconhecido, mas ameaçador que pudesse acontecer à parturiente, no processo de trabalho de parto e parto, bem como o medo de possíveis agravos foram narrados pelas mulheres, tais como: medo que lhe faltasse o ar na hora do parto, de não conseguir ter força para ir até o fim do trabalho de parto, de não ter força para empurrar o bebê. A preocupação com a saúde do bebê, especialmente quanto à integridade física, também foi reportada na quase totalidade das entrevistas.

A possibilidade de ficar só durante o trabalho de parto e parto, mencionada em alguns depoimentos, foi uma situação apontada pelas mulheres como sendo geradora de medo.

A pesquisadora registrou, com grande frequiência, verbalizações das parturientes, que se encontravam no estágio avançado do trabalho de parto, expressando sensações de desfalecimento, de desmaios iminentes, sensações essas acompanhadas de choro, gritos, gemidos, falas de que não iriam conseguir parir, episódios de agitação motora, tremores, alterações na fisionomia, presença de sudorese, esfriamento de mãos e pés.

No que diz respeito às relações interpessoais, as falas marcaram a importância da presença do outro nos momentos que antecederam o parto e no parto. Nos depoimentos das doulas foram identificadas, através de verbalizações e observações de suas práticas, disposições subjetivas de solicitude, acolhimento e diálogo no exercício de provimento dos cuidados. Contatos físico-corporais , providências como servir chá, alimentos, bem como permanecer ao lado conversando foram práticas citadasdas em todos os relatos.

A presença intermitente e/ou contínua, ou seja, ter tido sempre alguém por perto foi relatada, com destaque, pela quase totalidade das mulheres como uma qualidade diferencial e a mais apreciada das modalidades de atenção que receberam. Assim, as entrevistadas reportaram: terem sido influenciadas de modo positivo pela conversa com a doula; terem sentido segurança, confiança com a sua companhia; terem sido acompanhadas por alguém à semelhança de uma amiga ou mãe. As sensações de relaxamento e calma sobrevindas a partir da presença da doula, também foram prevalentes nos depoimentos daquelas parturientes acompanhadas continuamente.

Embora não tenha sido estabelecida como categoria de análise, a presença do parceiro e da família nos momentos que antecederam o parto, desde a saída de casa, apresentou-se relatada nos registros de observação e nas entrevistas, de modo significativo. O acompanhamento do marido, companheiro ou namorado, no momento do parto e/ou imediatamente após o parto, foi realçado, com satisfação, em muitas depoimentos.

\section{Discussão e considerações finais}

O tema da relação interpessoal apresentouse como espaço-eixo em torno do qual os cuidados foram processados, os sentimentos manifestados, algum conforto foi reencontrado, a palavra foi ouvida, a experiência compartilhada.

O contexto relacional mediado pelos cuidados de saúde e pelos processos comunicacionais 
que neles ocorreram assomam como aspectos privilegiados na compreensão procurada pelo estudo. Necessário se faz pontuar que o campo de tais cuidados instiga pensá-lo também na ótica das posições ou lugares que ocupam os sujeitos que dele participam, construindo significados, como indica a abordagem da análise do discurso de Brandão ${ }^{25}$, que destaca a relevância do "papel do sujeito falante no processo da enunciação" (Brandão, 2004). O recurso a tal abordagem implica atentar para as múltiplas determinações de ordem socioeconômica, política e cultural das relações entre os sujeitos na forja de seus discursos. Entende-se pois, pertinente propor que essas referências teóricas balizadoras colocam em perspectiva os temas concernentes ao campo das relações interpessoais e ao campo da linguagem.

As contribuições trazidas pela abordagem teórico-metodológica específica, nas áreas da Psicologia e Psicanálise, utilizada neste trabalho, podem ser vistas como inovadoras, no contexto dos estudos sobre o suporte emocional resultante do trabalho de acompanhamento contínuo às parturientes. Acredita-se, desse modo, que o recurso a alguns conceitos e temas referenciados ao campo desses saberes tais como as noções de sujeito, intersubjetividade, discurso ou práticas discursivas, entre outras, permitiu que a reflexão buscada alcançasse dimensões da intersubjetividade, tanto no contexto da relação dual, como também no quadro mais ampliado das relações sociais e institucionais, das quais aquelas não se acham dissociadas.

Com base nas considerações apresentadas seria lícito dizer que, no plano subjetivo e no âmbito circunscrito ao momento delimitado pelo estudo, as relações interpessoais delinearam conexões de subjetividades em torno de lugares distintos, mas complementares, a partir dos quais falaram os sujeitos envolvidos - o lugar do sujeito-alvo de cuidados e o lugar do sujeitoprovedor desses cuidados.

Os aspectos da subjetividade encontrados no âmbito da situação estudada, e corroborados na literatura consultada, autorizariam a falar de um espaço relacional que, do lado da parturiente, esteve marcado por um sujeito momentaneamente imerso na tensão provocada pelo medo, pela dor, suas vicissitudes e seus fantasmas. Provavelmente o espaço relacional, vivenciado nesta condição, configurou-se não apenas como um espaço onde se poderia endereçar demandas de alívio, de mitigação ou mesmo remissão do sofrimento, mas também como espaço de interlocução marcada pela escuta das demandas e de acolhimento daquilo que, falando no corpo da parturiente, fazia ressonâncias nas suas idéias e emoções.

Foi notável a presença de representações das parturientes de fortalecimento pessoal, de vitória, de coragem, por ter conseguido desincumbir-se, com êxito, do parto, isto é, do parto vaginal. Observou-se que a valorização recorrente da atenção recebida recaiu freqüentemente nos processos comunicacionais que implicaram diálogo, presença atenta, companhia solícita. A qualidade sintônica da relação parece ter se insinuado nessas percepções, associações, impressões e nos efeitos que as parturientes referiram como "influência" sobre o estado subjetivo vivido então. Desse modo, seria pertinente supor que a interferência da presença com tal qualidade no curso de um processo que se delineava como angustiante e doloroso, atenuando o alto grau de tensão, pôde alcançar, para além do efeito tranqüilizador, a possibilidade de acesso ao protagonismo dos sujeitos, então vulnerabilizados pelo estresse, nos processos que estavam vivenciando.

As declarações, repetidas nos relatos das parturientes, mencionando terem sido influenciadas, terem recebido "energia positiva" ou "uma força" das doulas e/ou obstetrizes, para levar a cabo o processo da parturição, parecem indicar a vivência de um processo relacional onde a escuta e o acolhimento foram não só valorizados, mas também sentidos como processo comunicacional que produziu consequiências. Assim, a qualidade atribuída aos cuidados permitem admitir a impressão de que a presença de interlocutores com as características apontadas acima produz atos capazes de ter efeitos favoráveis sobre as vivências da parturiente.

É importante considerar o contexto institucional das relações interpessoais, foco desse estudo. Por certo elas não se apresentaram apartadas dos limites e injunções da instituição onde ocorreram e deles receberam influxos. Desse 
modo, as assimetrias e descompassos observados no âmbito sociopolítico das relações colocam para a reflexão questões que merecem ser investigadas com mais acuidade, pois requerem referências teórico-metodológicas apropriadas às especificidades dessas questões.

A dimensão da sensibilidade no diálogo estabelecido, certamente é necessária e imprescindível ao trabalho de suporte, engrandecendoo. Para além dela, pode-se encontrar a dimensão da solidariedade, que se tornará mais fortalecida tanto mais seja sustentada e legitimada como exercício do direito a uma assistência, cuja qualidade passa também pelo acesso a recursos técnicos dessa natureza.

Colocar a relação interpessoal nesse patamar significa pensá-la como recurso, cuja especificidade pode torná-la equivalente àquelas ações ou procedimentos prescritos como tecnologias apropriadas na assistência ao parto. Significa pensá-la enquanto instrumento de ordem técnica e ética, no campo das práticas dos cuidados de saúde que se pretendem eficazes, seguras e comprometidas com os direitos de cidadania das mulheres.

\begin{abstract}
An important question that has been emphasized in studies on health care practices is the considerable influence of the relational dimension on the quality of the care provided. Various studies carried out in many countries have been pointing out the high value of emotional and social support in the pregnancy-puerperium cycle, especially during the labor process and delivery, with different forms of institutional support. According to such studies, emotional and social support is an important factor in the quality of the maternal care provided. This article presents results and considerations related to the theme of supportive care based on a study conducted in a maternity of São Paulo, state of São Paulo, Brazil, in 2004, using a qualitative methodology with semi-structured interviews and observation of routine activities of the institution. Data processing was based on categories especially built for analysis. The analysis showed the relevance of interpersonal relationships in the childbirth process. This has enabled us to apprehend the relational space as a privileged place for interlocution, marked by listening and acceptance of the experience the women are going through. This relational space may be considered of the utmost relevance, among other resources indicated as appropriate in delivery care.
\end{abstract}

Key words: Delivery. Labor. Support. Quality of health care.

\section{REFERENCIAS}

1. Tanaka AC d'A. Maternidade, dilema entre nascimento e morte. São Paulo: Hucitec; Rio de Janeiro: Abrasco; 1995.

2. Faúndes A, Cecatti JGA. Operação cesárea no Brasil: incidência, tendências, causas, consequiências e propostas de ação. Cad Saúde Pública. 1991;7(2):150-73.

3. Organização Mundial da Saúde. Assistência ao parto normal: um guia prático. Genebra; 1996.

4. Ministério da Saúde. Parto, aborto e puerpério: assistência humanizada à mulher.

Brasília (DF); 2001.

5. Brasil. Lei ${ }^{\circ} 11.108$, de dia de mês de ano. Altera a Lei n. 8.080, de 19 de setembro de 1990, para garantir às parturientes o direito à presença de acompanhante durante o trabalho de parto, parto e pós-parto imediato, no âmbito do Sistema Único de Saúde - SUS. Diário Oficial da União. 8 abr 2005;Seção:paginação. Faltam dia, mês e ano de aprovação da lei e Seção e paginação de publicação no DOU

6. Caprara A, Franco ALS. A relação pacientemédico: para uma humanização da prática médica. Cad Saúde Pública. 1999;15(13):647-54.

7. Missenard A, organizador. A experiência Balint: história e atualidade. São Paulo: Casa do Psicólogo; 1994. p. 9-22. Esta não seria a referência 10 , mas incompleta?

8. Winnicott DW. A experiência da mãe-bebê de mutualidade. In: Winnicott C, Shephred R, Davis M, organizadores. Explorações psicanalíticas D. W. Winnicott. Porto Alegre: Artes Médicas; 1994. p. 195-202.

9. Balint M. O médico, seu paciente e a doença. Rio de Janeiro: Atheneu; 1988. 
10. Balint M. Psicanálise e prática médica. In: Missenard A, organizador. A experiência Balint: história e atualidade. São Paulo: Casa do Psicólogo; 1994. p. 9-22.

11. Diniz CSG. Entre a técnica e os direitos humanos: possibilidades e limites da humanização da assistência ao parto [tese]. São Paulo: Faculdade de Medicina da Universidade de São Paulo; 2001.

12. Caton D, Corry M, Frigoletto FD, Hopkins DP, Lieberman E, Mayberry L. The nature and management of labor pain: executive summary. Am J Obstet Gynecol. 2002;186 Suppl 5:1-15.

13. Lowe NK. The nature of labor pain. Am J Obstet Gynecol. 2002;186 Suppl 5:16-24.

14. Soifer R. Psicologia da gravidez, parto e puerpério. Porto Alegre: Artes Médicas; 1992.

15. Noronha D. Gravidez: situação de crise. Rio de Janeiro: Revinter; 1997.

16. Maldonado MT, Canella P. A relação médicocliente em ginecologia e obstetrícia. Rio de Janeiro: Atheneu; 1981.

17. Langer M. Maternidade e sexo. Porto Alegre: Artes Médicas; 1986.

18. Klaus MH, Kennell JH. The doula: an essential ingredient of childbirth rediscovered. Acta Paediatr. 1997;86:1034-6.

19. Maternitywise. How do I get labor support I need?: best available research about labor companion [acesso em 17 jul 2003]. Disponível em: http://maternitywise.org/mw/ topics/laborsupport/evidence_body.htlm.

20. Hodnett ED, Gates S, Hofmeyr GJ, Sakala C. Continuous support for women during childbirth. Cochrane Database Syst Rev [periódico na Internet]. 2003 [acesso em dd mm aaaa];(3). Disponível em: http://cochrane.bireme.br cochraneshow.php?db=reviews $\& \mathrm{mfn}=582 \& \mathrm{id}=$ \&lang=pt\&dblang=.

21. Queiroz MIP. Variações sobre a técnica de gravador no registro da informação viva. São Paulo: T. A. Queiroz; 1991.

22. Minayo CSM. O desafio do conhecimento: pesquisa qualitativa em saúde. São Paulo: Hucitec; Rio de Janeiro: Abrasco; 1994.

23. Miles MB, Huberman AM. Qualitative data analysis. London: Sage; 1994.

24. Abbagnano N. Dicionário de filosofia. São Paulo: Mestre Jou; 1970.

25. Brandão HHN. Introdução à análise do discurso. Campinas: Unicamp; 2004.

Recebido em 31/10/2006 Aprovado em 14/11/2006 